\title{
Application of phycoremediation technology in the treatment of wastewater from a leather-processing chemical manufacturing facility
}

\author{
P Hanumantha Rao*, R Ranjith Kumar, BG Raghavan, VV Subramanian and V Sivasubramanian \\ Department of Plant Biology and Plant Biotechnology, R.K.M. Vivekananda College, Chennai 600004 , Tamil Nadu, India
}

\begin{abstract}
Phycoremediation is the use of algae for the removal or biotransformation of pollutants from wastewater. Employing this technology in the treatment of industrial effluents presents an alternative to the current practice of using conventional methods, including physical and chemical methods. In the present study, the effluent from a leather-processing chemical manufacturing facility, situated at Ranipet, Tamil Nadu, India, was treated using the microalga, Chlorella vulgaris, which was isolated from the effluent itself. The objective of this study was to treat the effluent as well as ETP (effluent treatment plant) solid waste by phycoremediation (pilot-scale field study as well as laboratory study) and to analyse the physico-chemical parameters before and after treatment. The results obtained showed that Chlorella vulgaris exhibited appreciable nutrient scavenging properties under both laboratory and field conditions, although phycoremediation carried out in sunlight (field study) gave better results. Moreover, the growth of Chlorella vulgaris was faster under field conditions.
\end{abstract}

Keywords: Phycoremediation, microalgae, Chlorella vulgaris, effluent, ETP solid

\section{Introduction}

Phycoremediation is the use of macroalgae or microalgae for the removal or biotransformation of pollutants, including nutrients and xenobiotics, from wastewater and $\mathrm{CO}_{2}$ from waste air (Olguin, 2003). Over the last few decades, efforts have been made to apply intensive microalgal cultures to perform the biological tertiary treatment of secondary effluents (Oswald and Gotaas, 1957; De la Noüe et al., 1992). The underlying assumption is that the microalgae will transform some of the contaminants into non-hazardous materials enabling the treated water to then be reused or safely discharged (Oswald, 1988). As microalgae use carbon dioxide as a carbon source, they can grow photoautotrophically without the addition of an organic carbon source. Unicellular green algae such as Chlorella spp. and Scenedesmus spp. have been widely used in wastewater treatment as they often colonise the ponds naturally and have fast growth rates and high nutrient removal capabilities. Thus, the use of microalgae for removal of nutrients from different wastes has been described by a number of authors (Beneman et al., 1980; De-Bashan et al., 2002; Gantar et al., 1991; Queiroz et al., 2007).

Microalgae offer a low-cost and effective approach to remove excess nutrients and other contaminants in tertiary wastewater treatment, while producing potentially valuable biomass, because of a high capacity for inorganic nutrient uptake (Bolan et al., 2004; Muñoz and Guieyssea, 2006). In a study by Zhang et al. (2008), Scendesmus sp. showed high removal efficiency for inorganic nutrients from artificial and real domestic secondary effluents. In addition, microalgae play an important role during the tertiary treatment of domestic wastewater in maturation ponds or the treatment of small- to middle-scale

\footnotetext{
* To whom all correspondence should be addressed.

픈 +91 9841910222; e-mail:dr.phrao@gmail.com

Received 23 April 2010; accepted in revised form 13 December 2010
}

municipal wastewater in facultative or aerobic ponds (Aziz and Ng, 1993; Mara and Pearson, 1986; Oswald, 1995). They have been used for removing nitrogen and phosphorus from wastewater (Oswald, 1988) and have the potential to be used to remove various pollutants, including oxides of nitrogen (NOx) (Nagase et al., 2001). Similarly, degradation of complex organic carbon substrates in tannery wastewater has been attempted in high-rate algal ponding systems (Dunn, 1998). Finally, if the purpose is to cultivate green biomass in the wastewater, microalgae would be a good alternative to chemical precipitation (Larsdotter, 2006).

Microalgae assimilate a significant amount of nutrients because they require high amounts of nitrogen and phosphorus for the synthesis of proteins (45-60\% of microalgal dry weight), nucleic acids and phospholipids. Nutrient removal can also be further increased by $\mathrm{NH}_{3}$ stripping or $\mathrm{P}$ precipitation due to the rise in the $\mathrm{pH}$ associated with photosynthesis (Laliberté et al., 1994; Nurdogan and Oswald, 1995; Oswald, 2003).

In the era of global warming, climate change and carbon crediting, there is grave concern about increasing carbon dioxide levels in addition to the laborious task of treating pollutant-containing wastes. Of late, microalgal cultures have been proposed for use in fixation of $\mathrm{CO}_{2}$, which is of interest in greenhouse gas mitigation and in production of biofuels. Algae considered as green-cell factories are not only good scavengers of toxic chemicals but are also involved in oxygenation of the atmosphere and carbon dioxide sequestration, thereby making them a better candidate among bioremediation systems. The development of this idea was first conceptualised by Oswald and Golueke (1960), who described a large-scale system with dozens of large ( $40 \mathrm{ha}$ ) high-rate ponds, with the algae grown and the biomass harvested by a simple flocculation-settling step, and the concentrated algal sludge anaerobically digested to produce biogas (methane and $\mathrm{CO}_{2}$ ).

Using microalgae in continuous treatment processes would be of great advantage, because most industries are in dire 
exigency for implementing cost-effective continuous treatment processes. Algal species are relatively easy to grow, adapt and manipulate within a laboratory setting and appear to be ideal organisms for use in remediation studies (Dresback et al., 2001). In addition, phycoremediation has advantages over other conventional physico-chemical methods, such as ion-exchange, reverse osmosis, dialysis and electro-dialysis, membrane separation, activated carbon adsorption, and chemical reduction or oxidation, due to its better nutrient removal efficiency and the low cost of its implementation and maintenance.

In the present study, the green microalga, Chlorella vulgaris, was used to treat the effluent of a leather-processing chemical manufacturing facility (a multinational company), situated at Ranipet, Tamil Nadu, India. The manufacturer is one of the world's leading suppliers of leather-processing products and also has a strong market niche in many proprietary products. Some of the products from the industry include polyurethane and acrylic resins, lacquers and lacquer emulsions, pigment dispersions, protein binders, wax emulsions and fillers, shoe finishes and dye formulations. The average total effluent generated per day by the factory amounts to approx. 25-30 k $\ell$. The characteristic raw effluent contains residual pigments, chemicals and heavy metals. Production of protein binders in the plant also results in the presence of some biological compounds such as casein. The constituents of the effluent vary according to the product manufactured in the particular batch. However, the heavy metals present in the effluent are well below alarming or hazardous levels. An already-existing effluent treatment plant (ETP) functioning inside the factory premises converts the pollutants into solid waste by polyelectrolyte precipitation and pressure filtration of the raw effluent. However, as a result of this treatment, tons of ETP solid waste which has been separated from the effluent have accumulated over the years. The filtered water is passed onto the aeration tank before being passed through a series of clarifying settlers and finally filtered through dual media filter (primary sand filter and activated carbon filter). In this study, we made an attempt to treat the effluent as well as ETP solid waste by phycoremediation technology using C. vulgaris. Physicochemical parameters of the effluent and ETP solid waste (heavy metal study to be published separately) before and after treatment were analysed. We conducted the study in both laboratory and in situ field conditions.

\section{Materials and methods}

\section{Isolation and culturing of microalgae}

Chlorella vulgaris Beij. was isolated from the effluent using serial dilution, standard plating, colony isolation and culture techniques. The monograph of Philipose (1967) was used for the identification of the microalga. An axenic culture of C. vulgaris was maintained in Bold's basal medium (BBM) (Nichols and Bold, 1965) at $24 \pm 1^{\circ} \mathrm{C}$ in a thermostatically controlled environmental chamber illuminated with cool white fluorescent lamps (Philips $40 \mathrm{~W}$, cool daylight, $6500 \mathrm{~K}$ ) at an intensity of 2000 lux in a 12/12 h light/dark cycle. For outdoor cultivation of the microalga, improvised CFTRI medium (Venkataraman and Becker, 1985) with slight modifications was used.

Improvised CFTRI medium was used for field studies because the chemicals used were of low cost and commercial grade and the medium has been well established for outdoor cultivation by the above-mentioned authors.

\section{Laboratory trials}

Exponential phase cells of $C$. vulgaris (growth determined by cell count method using a haemocytometer) were centrifuged and the washed pellet was re-suspended in $2 \ell$ of the diluted effluent ( 5 times with BBM) in a conical flask bioreactor and incubated in the above-mentioned conditions for 7 days. The effluent sample was analysed for physico-chemical parameters before and after treatment according to the method of APHA (2000). In the treated effluent, algal cells were separated by centrifugation before analysis.

\section{Field trials}

\section{High-rate Algal Pond (HRAP)}

The concept of the HRAP was developed by Oswald et al. (1957) in the mid 1950s and is in place in various countries around the world. In subsequent decades, the HRAP was used in effluent treatment by many authors, for example, by Rose et al. (1996) in the treatment of tannery wastewaters. Later, integrated algal ponding systems, a combination of ponding system units involving an algal component in their operation, began to be used in the treatment of winery and distillery wastewaters (Rose, 2002). In this study, an HRAP was constructed inside the factory premises with a wall thickness of $0.12 \mathrm{~m}$. The inner dimensions of the pond were such that the length was $3.65 \mathrm{~m}$ and the width was $1.80 \mathrm{~m}$. The depth of the pond was kept at $0.44 \mathrm{~m}$ to allow sufficient light penetration for the growth of algae. A partition wall was constructed in the middle of the pond for a length of $2.46 \mathrm{~m}$ and width of $0.12 \mathrm{~m}$. The floor was constructed with a slight slope on either side of the partition in the opposite direction, to enable proper mixing of the culture. The inside of the pond wall was lined with white tiles to prevent seepage of the medium into the wall and for a better visual observation of algal growth. This also aids in sunlight reflection and thereby provides more light for microalgal growth. The pond was provided with a tap water connection for preparation of the medium and 2 outlets were provided to enable cleaning the pond. The pond contents were manually mixed 3 times a day to ensure proper dispersion of nutrients and better aeration.

\section{Sloping pilot pond}

The principle of the sloping design is to create a turbulent flow while the algal suspension flows across the sloping surfaces or trenches present in the slope. A pump returns the algal medium from the lowest point to the top of the slope. The turbulence is produced by gravity, according to the flow speed of the liquid given by the slope of the surface (Becker, 1994). The pilot sloping pond was constructed with dimensions similar to those of the HRAP. A sloping angle made of GI (galvanised iron) sheeting was fixed over the open HRAP at an angle of $15^{\circ}$. The advantages of the sloping pond include enhanced sunlight exposure to the individual algal cell and aeration so that microalgal growth can be hastened. In addition, it creates homogeneous suspension of the nutrients. The major advantage of this design is the fact that, with the exception of a pump with low pressure, no other mechanical device is required. One centimetre of water in the pond equalled $70 \ell$. During the trial, the flow rate was standardised to $800 \mathrm{\ell} / \mathrm{h}$ by a trial-and-error method and the plant was run for $9 \mathrm{~h}$ during the day.

\section{Field trials with the effluent using $\mathrm{C}$. vulgaris}

Chlorella vulgaris was grown in $1 \mathrm{k} \ell$ of improvised CFTRI medium in the HRAP and allowed to reach the exponential 
phase; $200 \ell$ of the effluent was added to it and, prior to its addition, the same quantity of the culture was pumped out so that the final volume remained unchanged. Addition of the effluent was carried out after standardising the growth rates in various dilutions in our laboratory experiments. The dilution of the effluent with the medium was performed in order to supplement the algae with additional nutrients. The microalga was allowed to grow for 5 days. Physico-chemical parameters of the pre- and post-treated effluent were analysed after separating the algal biomass from the treated effluent by the auto-settling method. In addition, sludge removal capacity of $C$. vulgaris was studied on a daily basis for 5 days by the dry weight method (dried at $105^{\circ} \mathrm{C}$ until obtaining concordant weights).

\section{Field trials with the ETP solid using C. vulgaris}

Chlorella vulgaris was allowed to grow in $1 \mathrm{k} \ell$ of improvised CFTRI medium in the sloping pilot pond. ETP solid treatment was carried out in the sloping pilot pond so as to provide continued mixing, because discontinuous mixing will result in very quick settling of the sludge. To the logarithmic phase culture, $1 \%$ of ETP solid was added and mixed to obtain a homogeneous suspension of ETP solid waste. The percentage was standardised after performing laboratory experiments on growth rates. After 5 days, the physico-chemical parameters were analysed and before- and after-treatment values were compared; the algal biomass was separated before analysis from the treated ETP solid suspension by the auto-settling method.

Sludge removal in ETP solid samples using $\mathrm{C}$. vulgaris To study the tolerance and survival limits of $C$. vulgaris in high sludge concentrations, $5 \%$ suspension of ETP solid waste (which is approximately equivalent to the raw effluent) was prepared in the logarithmic phase culture of $C$. Vulgaris in the sloping pilot pond. Sludge concentrations were measured by the dry weight method as described earlier for 5 days on a daily basis.

\section{pH stabilisation study using $\mathrm{C}$. vulgaris}

Chlorella vulgaris was grown in $1 \mathrm{k} \ell$ of improvised CFTRI medium in the HRAP. On reaching the exponential phase, $100 \ell$ of the logarithmic phase culture was replaced with the same quantity of the effluent. After 5 days, the effluent load was increased to $200 \ell$ and subsequent additions of $100 \ell$ once every 5 days were made so that the effluent load became $500 \ell$ in 20 days. pH was monitored using a pH meter (Elico LI 120; Hyderabad, India) for 25 days from Day 0 to Day 25.

\section{Statistical analysis}

Values of all data are expressed as mean $\pm \mathrm{SD}$. The one-tailed paired Student's $t$-test was used to determine statistical significance between the untreated and treated parameters at $P<0.05$. All analyses were carried out in triplicate.

\section{Results}

\section{Phycoremediation of effluent - laboratory study}

The results of the laboratory study are presented in Table 1, after multiplying the values by the dilution factor. At the end of the phycoremediation using C. vulgaris, i.e., on day 7, $\mathrm{pH}$ of the effluent increased from 7.6 to 8 and maintained thereafter, while total dissolved solids (TDS) was slightly reduced by $1.3 \%$. The microalgal treatment resulted in a significant reduction in total hardness by about $50 \%$. Calcium and magnesium also followed a similar trend with $63 \%$ and $50 \%$ reductions respectively. Sodium and potassium, which form an important constituent of inorganic TDS, were only reduced to a small extent, by around $14 \%$ and $18 \%$, respectively. Free ammonia levels were reduced by $80 \%$, nitrite levels by $89 \%$, nitrates by $29 \%$ and total Kjeldahl nitrogen (TKN) by $73 \%$. Phosphate levels were drastically reduced by $94 \%$. Reductions in biochemical oxygen demand (BOD) and chemical oxygen demand (COD) levels were $22 \%$ and $38 \%$, respectively, during the phycoremediation process.

\begin{tabular}{|c|c|c|c|}
\hline \multicolumn{4}{|c|}{$\begin{array}{c}\text { Table } 1 \\
\text { Physico-chemical analysis of effluent - phycoremediation (laboratory trials) } \\
\text { using C. vulgaris }\end{array}$} \\
\hline S.No. & Parameters & Day 0 & Day 7 \\
\hline 1 & 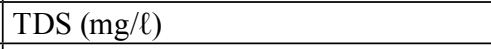 & $2725 \pm 10.3923$ & $2690 \pm 6.0828$ \\
\hline 2 & Electrical conductivity $(\mu \mathrm{mho} / \mathrm{cm})$ & $3824 \pm 13.1149$ & $3768 \pm 6.5574$ \\
\hline 3 & $\mathrm{pH}$ & $7.6 \pm 0.0173$ & $8 \pm 0.1323$ \\
\hline 4 & Total hardness $\left(\right.$ as $\left.\mathrm{CaCO}_{3}\right) \mathrm{mg} / \ell$ & $1000 \pm 19.975$ & $500 \pm 10.5357$ \\
\hline 5 & Calcium (as $\mathrm{Ca}$ ) $\mathrm{mg} / \ell$ & $240 \pm 12.53$ & $90 \pm 13.7477$ \\
\hline 6 & Magnesium (as Mg) $\mathrm{mg} / \ell$ & $90 \pm 4.3589$ & $45 \pm 5.2915$ \\
\hline 7 & Sodium (as Na) $\mathrm{mg} / \ell$ & $550 \pm 15.1328$ & $450 \pm 13.4536$ \\
\hline 8 & Potassium (as $\mathrm{K}$ ) $\mathrm{mg} / \ell$ & $35 \pm 3.6056$ & $30 \pm 4.3589$ \\
\hline 9 & Total Kjeldahl Nitrogen (TKN) mg/ $\ell$ & $55 \pm 4.5826$ & $15 \pm 3.6056$ \\
\hline 10 & Free ammonia (as $\mathrm{NH}_{3}$ ) $\mathrm{mg} / \ell$ & $56.3 \pm 7.0633$ & $11.5 \pm 1.5133$ \\
\hline 11 & Nitrite $\left(\right.$ as $\left.\mathrm{NO}_{2}\right) \mathrm{mg} / \ell$ & $0.045 \pm 0.0078$ & $0.005 \pm 0.0002$ \\
\hline 12 & Nitrate (as $\mathrm{NO}_{3}$ ) $\mathrm{mg} / \ell^{*}$ & $7 \pm 1.7321$ & $5 \pm 1$ \\
\hline 13 & Phosphate $\left(\right.$ as $\left.\mathrm{PO}_{4}\right) \mathrm{mg} / \ell$ & $78.09 \pm 7.1383$ & $4.56 \pm 1.3159$ \\
\hline 14 & BOD $(\mathrm{mg} / \mathrm{\ell})$ & $230 \pm 14.4222$ & $180 \pm 7.5498$ \\
\hline 15 & $\mathrm{COD}(\mathrm{mg} / \ell)$ & $582 \pm 12.49$ & $360 \pm 13.2288$ \\
\hline
\end{tabular}

All values are presented as mean $\pm S D$ of triplicate analyses. Initial and final concentrations are statistically significant except nitrate ${ }^{*}$ - not significant (NS)) at $P<0.05$ according to one-tailed paired Student's t-test. The non-significance is due to the low initial concentration of nitrate. 


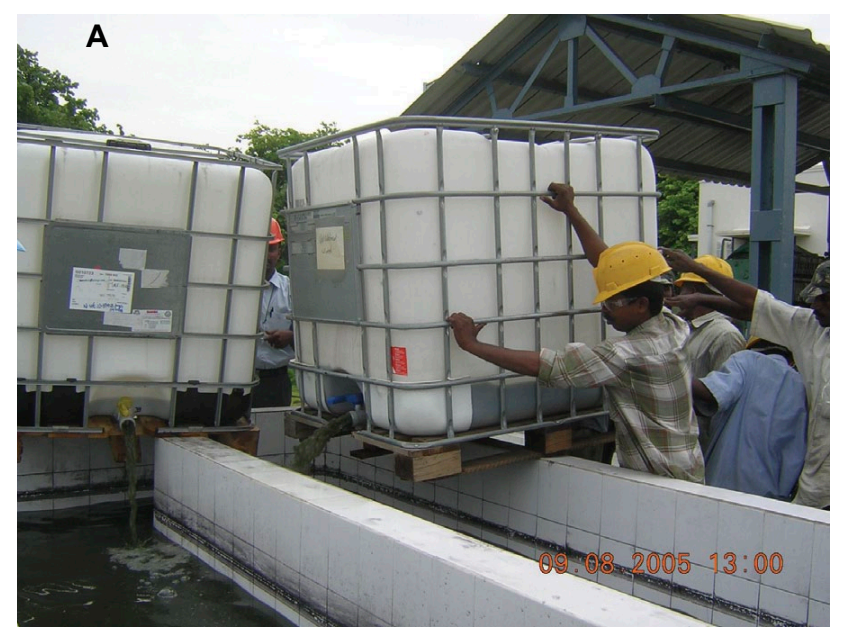

\section{Field studies}

\section{Phycoremediation of effluent}

The photographs of field trials at the factory site are shown in Fig. 1, and the results are given in Table 2, after multiplying the values by the dilution factor. After phycoremediation of the effluent using C. vulgaris, TDS, an important physical parameter for the discharge of the effluent, decreased by about $21 \%$ and electrical conductivity directly related to TDS also showed a similar pattern. Regarding chemical parameters, $\mathrm{pH}$ of the effluent increased from 7.9 to 8.3 and remained stable thereafter. Reduction in total hardness by approximately $83 \%$, in turn, accounted for $82 \%$ and $85 \%$ reductions in calcium and magnesium levels, respectively. With respect to other inorganic cations, a small amount of reduction in sodium and potassium was observed. The phosphate levels were reduced by $99 \%$, which is considered as a reduction to almost nil.
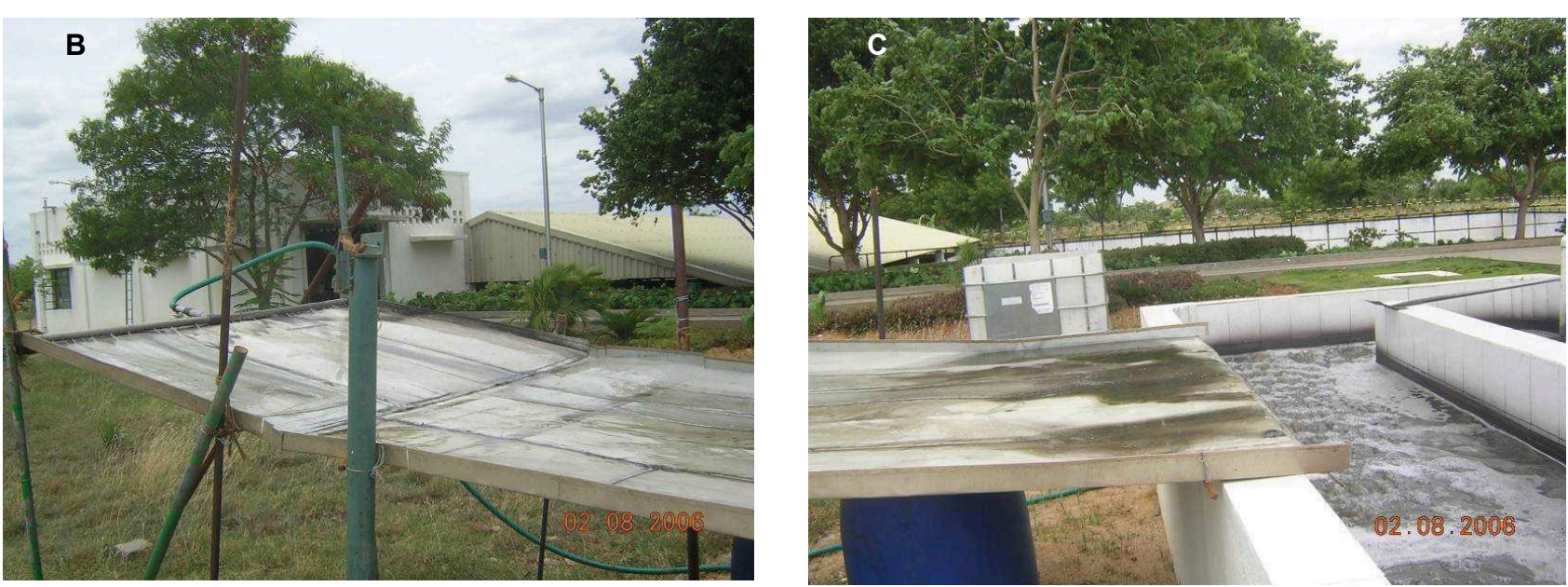

Figure 1

Photographs showing in situ field trials being carried out at the leather-processing chemical industry. Fig. 1A: Charging C. vulgaris culture in HRA pond; Fig. 1B and 1C: Pilot-scale sloping pond.

\begin{tabular}{|c|c|c|c|}
\hline \multicolumn{4}{|c|}{$\begin{array}{c}\text { Table } 2 \\
\begin{array}{c}\text { Physico-chemical analysis of effluent - phycoremediation (field trials) } \\
\text { using C. vulgaris }\end{array}\end{array}$} \\
\hline S.No. & Parameters & Day 0 & Day 5 \\
\hline 1 & 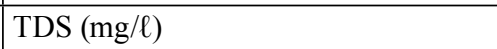 & $3226 \pm 28.1603$ & $2544 \pm 31.5119$ \\
\hline 2 & Electrical conductivity $(\mu \mathrm{mho} / \mathrm{cm})$ & $4076 \pm 18.3576$ & $3621 \pm 23.516$ \\
\hline 3 & $\mathrm{pH}$ & $7.9 \pm 0.0529$ & $8.33 \pm 0.0458$ \\
\hline 4 & Total hardness (as $\left.\mathrm{CaCO}_{3}\right) \mathrm{mg} / \ell$ & $750 \pm 18.0278$ & $126 \pm 9.6437$ \\
\hline 5 & Calcium (as Ca) $\mathrm{mg} / \ell$ & $170 \pm 7.5498$ & $30 \pm 2.6458$ \\
\hline 6 & Magnesium (as Mg) mg/ $\ell$ & $78 \pm 2.6458$ & $12 \pm 1.7321$ \\
\hline 7 & Sodium (as Na) $\mathrm{mg} / \ell$ & $525 \pm 11.1355$ & $400 \pm 13.4536$ \\
\hline 8 & Potassium (as K) $\mathrm{mg} / \ell$ & $75 \pm 4.5826$ & $70 \pm 2.6458$ \\
\hline 9 & Total Kjeldahl Nitrogen $(\mathrm{TKN}) \mathrm{mg} / \ell$ & $39.2 \pm 2.5851$ & $10.08 \pm 0.7219$ \\
\hline 10 & Free ammonia $\left(\right.$ as $\left.\mathrm{NH}_{3}\right) \mathrm{mg} / \ell$ & $38.08 \pm 1.9047$ & $6.72 \pm 0.5188$ \\
\hline 11 & Nitrite $\left(\right.$ as $\left.\mathrm{NO}_{2}\right) \mathrm{mg} / \ell$ & $0.62 \pm 0.0721$ & $0.32 \pm 0.0436$ \\
\hline 12 & Nitrate $\left(\right.$ as $\left.\mathrm{NO}_{3}\right) \mathrm{mg} / \ell$ & $33 \pm 1.7321$ & $25 \pm 3.6056$ \\
\hline 13 & Phosphate $\left(\right.$ as $\left.\mathrm{PO}_{4}\right) \mathrm{mg} / \ell$ & $71.91 \pm 2.8407$ & $0.50 \pm 0.0361$ \\
\hline 14 & 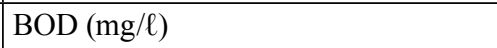 & $260 \pm 13.2288$ & $120 \pm 8.6603$ \\
\hline 15 & COD $(\mathrm{mg} / \ell)$ & $754 \pm 11.5326$ & $380 \pm 13.0767$ \\
\hline
\end{tabular}

All values are presented as mean $\pm S D$ of triplicate analyses. Initial and final concentrations are statistically significant at $P<0.05$ according to one-tailed paired Student's t-test. 


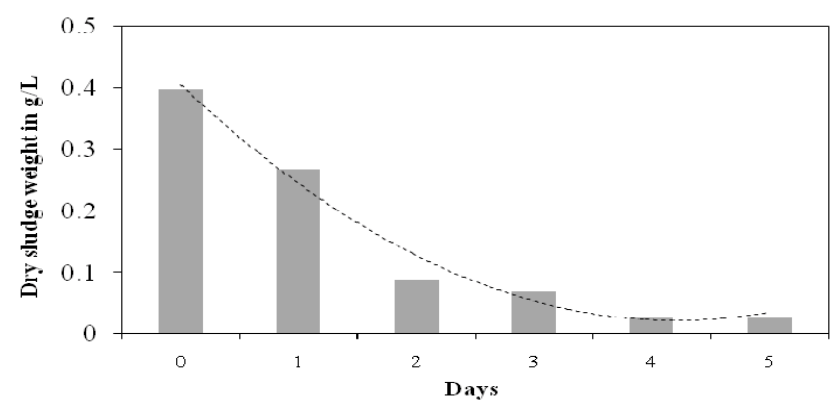

Figure 2

Histogram showing sludge reduction in the effluent using C. vulgaris. The trend clearly shows a decrease in sludge levels over a period of 5 days.

During the phycoremediation process, TKN, which includes most of the organic nitrogen, reduced by $74 \%$ and thereby resulted in a decrease in ammonia by $82 \%$. Nitrites and nitrates, constituents of inorganic nitrogen, were reduced by $48 \%$ and $24 \%$ respectively. The reductions in BOD and COD levels were almost similar and were approximately $50 \%$.

With respect to sludge reduction, the initial dry weight of the sludge on the inoculated day, which was around $0.4 \mathrm{~g} / \ell$, was drastically reduced by $93 \%$ on the final day (Fig. 2). This study exhibited good sludge removal potential of $C$. vulgaris during effluent treatment.

Phycoremediation carried out in field conditions was considered better because of the increased nutrient removal efficiency rates when compared with that of the indoor study. The field study treatment was far superior in reducing the majority of inorganic parameters such as total hardness, calcium, magnesium, sodium, potassium, nitrites and nitrates. Overall, outdoor treatment was considered to be a success and this can be attributed to the sunlight factor. In the pilot-scale field study, the minimum light intensity was 15000 lux and the maximum 75000 lux (morning - 25000 lux, noon - 75000 lux and evening - 15000 lux), whereas artificial illumination provided inside the laboratory was around 2000 to 4000 lux. Moreover, aeration was better in the field conditions due to regular manual mixing and also due to the mixing created by wind movement (Becker, 1994), thereby resulting in a homogeneous nutrient mixture, increased exposure of algal cells to sunlight and improved aeration.

\section{Phycoremediation of ETP solid waste}

\section{Removal of colour and odour}

During the phycoremediation of the ETP solid dissolved sample, the pitch black colour prior to the treatment completely transformed into a pleasant green colour, which almost looked like an algal culture (Fig. 3). Microscopical examination revealed the dominance of $C$. vulgaris cells with very minimal sludge (Fig. 4). In addition, the phycoremediation process resulted in a rich algal smell thereby completely removing the offensive smell of the sample.

\section{Physico-chemical analysis}

The results of the ETP solid treatment study are shown in Table 3. After the treatment of the ETP solid sample, TDS was reduced by $14 \%$ and the electrical conductivity showed a similar pattern with a reduction of about $15 \%$. As regards the chemical parameters, the treatment yielded very encouraging results. Effluent $\mathrm{pH}$, which was initially at 8.08 , rose to 8.55 .

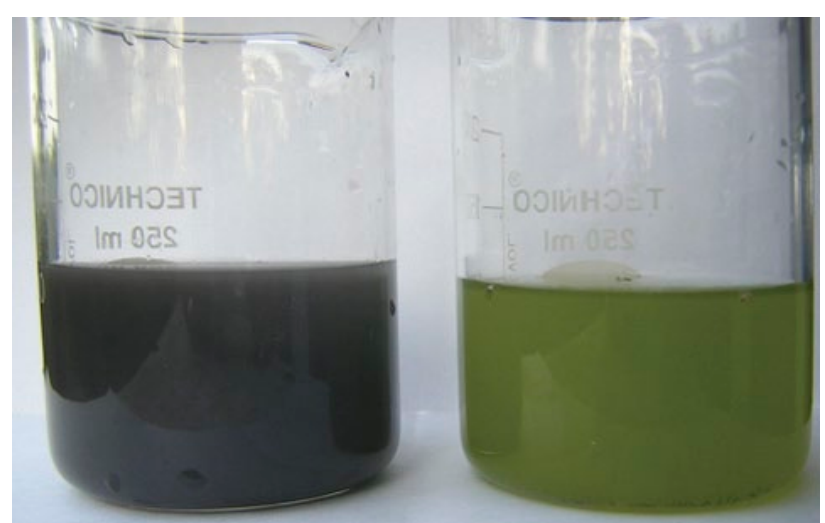

Figure 3

Photograph showing the dissolved ETP solid before and after phycoremediation. Before treatment, the dissolved ETP solid, which was black in colour, turned to green due to rich algal growth.

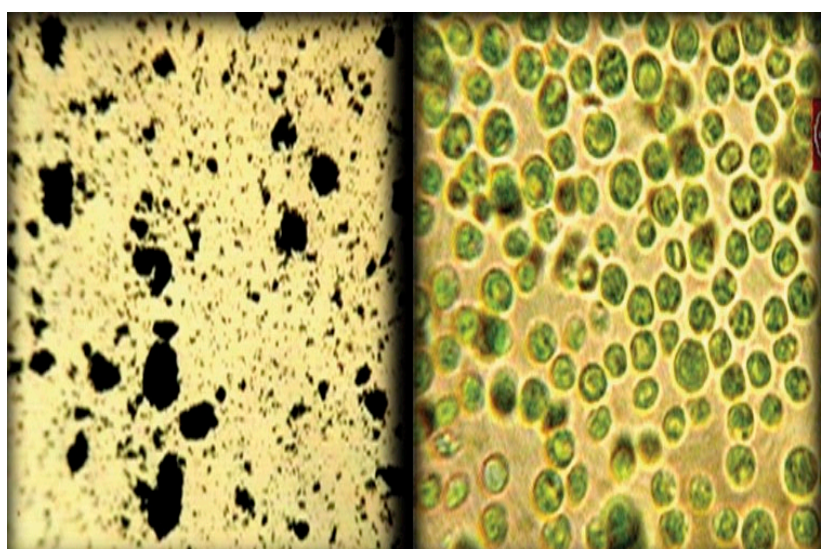

Figure 4

Photomicrograph showing the dissolved ETP solid before and after phycoremediation. Before treatment: ETP solid with smaller number of $\mathrm{C}$. vulgaris cells (picture on the left). After treatment:

C. vulgaris cells distributed throughout the microscopic field with the presence of very minimal sludge (picture on the right).

A decrease in total hardness by $35 \%$ was also accompanied by $26 \%$ and $46 \%$ reductions in calcium and magnesium, respectively. Potassium was reduced significantly, while sodium levels were slightly reduced. Phosphates were totally utilised during the treatment.

TKN was reduced by $12 \%$ and ammonia levels by $29 \%$. Nitrites and nitrates were decreased by $88 \%$ and $84 \%$ respectively. The reduction in the levels of BOD and COD was highly significant and followed a similar trend, of an approx. $83 \%$ reduction

\section{Sludge removal}

Initial dry sludge weight was about $11.33 \mathrm{~g} / \ell$ and was measured everyday for up to 5 days (Fig. 5). The trend showed a nearly $50 \%$ reduction in dry sludge during the first 2 days. Thereafter, the sludge levels were reduced by $95 \%$ on the $5^{\text {th }}$ and concluding day of the trial.

\section{Stabilisation of $\mathrm{pH}$ in the effluent}

Initial $\mathrm{pH}$ of the effluent, which was 7.1, increased steadily to 8.15 in 5 days after the addition of $C$. vulgaris culture. However, after gradual increase, $\mathrm{pH}$ was maintained at around 


\begin{tabular}{|c|c|c|c|}
\hline \multicolumn{4}{|c|}{$\begin{array}{c}\text { Table } 3 \\
\text { Physico-chemical analysis of ETP solid samples - phycoremediation (field trials) using C. vulgaris }\end{array}$} \\
\hline S.No. & Parameters & Day 0 & Day 5 \\
\hline 1 & TDS (mg/e) & $3214 \pm 12.49$ & $2772 \pm 8.8882$ \\
\hline 2 & Electrical conductivity $(\mu \mathrm{mho} / \mathrm{cm})$ & $4561 \pm 13.4536$ & $3876 \pm 14.1775$ \\
\hline 3 & $\mathrm{pH}$ & $8.08 \pm 0.0872$ & $8.55 \pm 0.04583$ \\
\hline 4 & Total hardness $\left(\right.$ as $\mathrm{CaCO}_{3}$ ) $\mathrm{mg} / \ell$ & $500 \pm 14.4222$ & $323 \pm 11.7898$ \\
\hline 5 & Calcium (as Ca) $\mathrm{mg} / \ell$ & $110 \pm 6.245$ & $81 \pm 5.5678$ \\
\hline 6 & Magnesium (as Mg) $\mathrm{mg} / \ell$ & $54 \pm 1.7321$ & $29 \pm 2.6458$ \\
\hline 7 & Sodium (as Na) $\mathrm{mg} / \ell$ & $880 \pm 4.3589$ & $800 \pm 8.6603$ \\
\hline 8 & Potassium (as K) $\mathrm{mg} / \ell$ & $150 \pm 2.6458$ & $70 \pm 3.4641$ \\
\hline 9 & Total Kjeldahl nitrogen $(\mathrm{TKN}) \mathrm{mg} / \ell$ & $72.8 \pm 1.9079$ & $63.84 \pm 3.4628$ \\
\hline 10 & Free ammonia $\left(\mathrm{as} \mathrm{NH}_{3}\right) \mathrm{mg} / \ell$ & $70.56 \pm 1.8112$ & $50.4 \pm 1.386$ \\
\hline 11 & Nitrite $\left(\right.$ as $\left.\mathrm{NO}_{2}\right) \mathrm{mg} / \ell$ & $0.85 \pm 0.0794$ & $0.10 \pm 0.0265$ \\
\hline 12 & Nitrate $\left(\right.$ as $\left.\mathrm{NO}_{3}\right) \mathrm{mg} / \ell$ & $19 \pm 2$ & $3 \pm 0.1732$ \\
\hline 13 & Phosphate $\left(\right.$ as $\left.\mathrm{PO}_{4}\right) \mathrm{mg} / \ell$ & $83.66 \pm 1.9765$ & $0.16 \pm 0.0265$ \\
\hline 14 & BOD (mg/l) & $210 \pm 8.6603$ & $35 \pm 5$ \\
\hline 15 & COD (mg/l) & $602 \pm 11.5326$ & $103 \pm 6.9282$ \\
\hline
\end{tabular}

All values are presented as mean $\pm S D$ of triplicate analyses. Initial and final concentrations are statistically significant at $P<0.05$ according to one-tailed paired Student's t-test.

8.6 (Fig. 6). Even after 25 days, i.e., even during gradual increase in the load of the effluent, $\mathrm{pH}$ was stable and was well within the discharge limits; this study has showed that phycoremediation technology has a wider scope in $\mathrm{pH}$ regulation, apart from nutrient removal capabilities. Thus, the buffering capacity of the microalgae remained, even during the addition of effluent, suggesting the potential of $C$. vulgaris in continuous treatment of the effluent.

\section{Discussion}

In this study, C. vulgaris has been shown to possess excellent nutrient scavenging capability. During the phycoremediation process, $\mathrm{pH}$ levels increased initially and thereafter remained around 8 . The microalga reduces dissolved $\mathrm{CO}_{2}$ concentrations through photosynthesis which, in turn, raises the $\mathrm{pH}$ level. The inorganic species normally used by microalgae are $\mathrm{CO}_{2}$ and bicarbonate (Borowitzka, 1998), the latter requiring the enzyme carbonic anhydrase to convert it to $\mathrm{CO}_{2}$. Furthermore, the $\mathrm{pH}$ levels are maintained so that there will be no increase in ammonia concentrations. Ammonia concentrations in the effluent and the $\mathrm{pH}$ are related by the following equilibrium relationship:

$$
\mathrm{NH}_{3}+\mathrm{H}_{2} \mathrm{O}<\longrightarrow \mathrm{NH}_{4}^{+}+\mathrm{OH}^{-}
$$

A high $\mathrm{pH}$ above 9 would move the equilibrium to the left and raise the ammonia concentration. Hence, $\mathrm{pH}$ stabilisation during microalgal treatment not only keeps the ammonia levels in check but also makes the effluent $\mathrm{pH}$ level conform to discharge standards ( $\mathrm{pH}$ 6-9). Total dissolved solids content of the effluent decreased upon treatment, which is due to the utilisation of various nutrients by $C$. vulgaris. The quantification might project reduced reduction levels because there could be a conversion of the total suspended solids already present in the effluent into dissolved materials for algal uptake and assimilation.

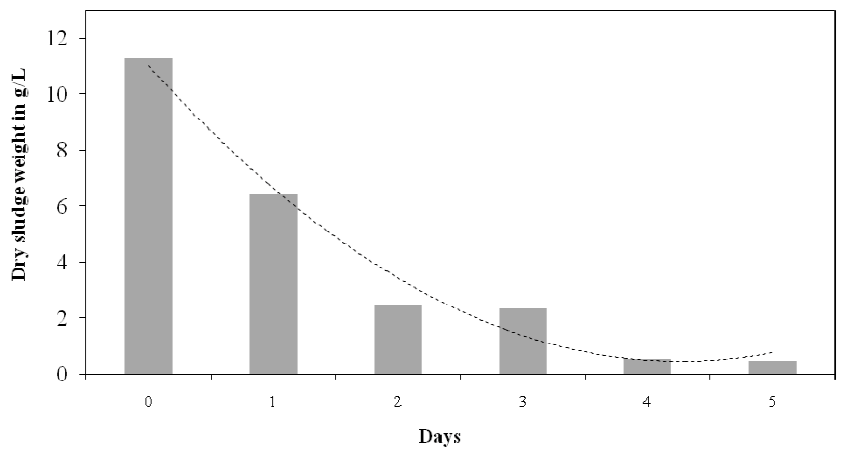

Figure 5

Histogram showing sludge reduction in the dissolved ETP solid waste using $\mathrm{C}$. vulgaris. The trend clearly shows a decrease in sludge levels over a period of 5 days.

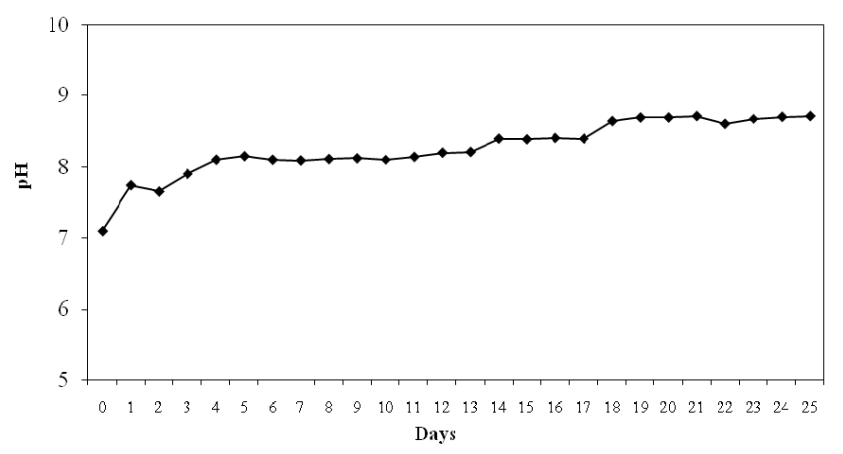

Figure 6

Graph showing the $\mathrm{pH}$ levels during the phycoremediation process over a period of 25 days. After an initial increase in $\mathrm{pH}$, the values stabilised around 8.6, which was well within the discharge standards. 
Nitrogen is another crucial parameter and is becoming increasingly important in wastewater management because nitrogen can have many effects on the environment (HallingSørensen and Jørgensen, 1993). Nitrogen can exist in different forms because of various oxidation states, and it can readily change from one form to another depending on the oxidation state present at the time. In the environment, living organisms can accomplish changes from one oxidation state to another. The principal forms of nitrogen are organic nitrogen, ammonia $\left(\mathrm{NH}_{4}^{+}\right.$or $\left.\mathrm{NH}_{3}\right)$, nitrite $\left(\mathrm{NO}_{2}^{-}\right)$and nitrate $\left(\mathrm{NO}_{3}^{-}\right)$.

The presence of nitrogen in wastewater during discharge can be undesirable because it has ecological impacts and can affect public health. Ammonia is extremely toxic and also an oxygen-consuming compound, which can deplete the dissolved oxygen in water. Although nitrate itself is not toxic, its conversion to nitrite is a concern in the domain of public health. Nitrite is a potential public health hazard (Sedlak, 1991) and, in the body, can oxidise iron (II) and form methaemoglobin, which binds oxygen less effectively than normal haemoglobin. All forms of nitrogen are taken up as a nutrient by the microalga, although the most common nitrogen compounds assimilated by microalgae are ammonium $\left(\mathrm{NH}_{4}^{+}\right)$and nitrate $\left(\mathrm{NH}_{3}^{-}\right)$ (Oliver and Ganf, 2000). In our study, C. vulgaris was able to reduce all forms of nitrogen substantially, and ammonia and nitrate levels, in particular, were drastically reduced. Ammonia may also be stripped off into the air as a result of the increased $\mathrm{pH}$ values often found in algal cultures (Nunez et al., 2001). There is not much of a concern regarding nitrite values in the context of the present study because the levels are very low in the effluent, and nitrite often occurs as an intermediate during nitrification processes.

Phosphate removal by $C$. vulgaris during phycoremediation is due to the utilisation of phosphorus for growth. The phosphorus, which is used in the algal cells mainly for production of phospholipids, adenosine triphosphates (ATP) and nucleic acids, gets assimilated as inorganic orthophosphate, preferably as $\mathrm{H}_{2} \mathrm{PO}_{4}^{-}$or $\mathrm{HPO}_{4}^{2-}$, and the uptake process is active, i.e. it requires energy (Becker, 1994). The chemical stripping of phosphorus may be regarded as an advantageous side-effect of the algal growth, with enhanced phosphorus removal as a result. The investigation revealed that the phosphate removal efficiency of C. vulgaris was nearly $100 \%$ in both the wastewater and ETP solid treatment processes. These phosphates were removed by photosynthetic assimilation and calcium phosphate precipitation because of high $\mathrm{pH}$ levels caused by intense algal photosynthetic activity (Hammouda et al., 1994). Moreover, microalgae are able to assimilate phosphorus in excess, which is stored in the cells as polyphosphate granules, and magnesium and potassium are co-transported along with phosphate (Bitton, 1990). During phycoremediation using $C$. vulgaris, a drastic reduction in magnesium levels and moderate decrease in potassium levels was observed. Although sodium levels did not show appreciable change, there was a significant reduction in calcium concentrations. This is aided by the carbonate ions, which not only decrease the crystallinity of calcium phosphates and promote the formation of amorphous calcium phosphates but also compete with phosphates in precipitating with calcium to form calcite $\left(\mathrm{CaCO}_{3}\right)$ at $\mathrm{pH}$ values above 8 (Arvin, 1983). However, sodium levels were reduced due to the tendency of the microalga for bioaccumulation. In addition, $C$. vulgaris induced progressive reduction in both BOD and COD values of the effluent and this could be attributed to the high algal growth rate and intense photosynthetic activity (Colak and Kaya, 1988).
Sludge reduction by $C$. vulgaris in the effluent as well as in ETP solid is of great significance because all other conventional methods, including other bioremediation methods, generate enormous sludge. In fact, the industry has accumulated tons of solid waste over the years through their already-existing conventional treatment methods. Thus sludge generation is not only a problem to this particular industry but also to many processing industries. Hence, for effective treatment with minimal sludge generation, phycoremediation offers ample scope for the future.

The benefits of phycoremediation can be summarised as follows:

- Ability of microalgae to tackle more than one problem simultaneously, a solution not possible by conventional chemical processes

- Case-specific as the process can be operated batch-wise, semi-continuously or in a continuous manner

- Commercial benefits derived from the biomass and other extracted biochemicals

- Compatibility with existing operations

- Cost-effective as it saves power and a lot of chemicals

- $\mathrm{CO}_{2}$ sequestration - a solution for the threat of global warming

- Flexibility to handle fluctuations in quality and quantity of effluent feed

- Oxygenation of environment

- Possible co-production of biofuels and biofertilisers

- Robust to minimise automation, maintenance and the need for skilled operators

- Selective to remove only the contaminants under consideration

- Sustainability and eco-friendliness from an ecological perspective.

Therefore, further studies are warranted on the less-explored phycoremediation technology for implementation at an industrial level.

\section{Conclusions}

The following conclusions can be drawn from this study:

- Chlorella vulgaris exhibited appreciable nutrient removal capacities

- Pilot-scale field studies proved that phycoremediation under field conditions (i.e. in sunlight) is far better than under laboratory conditions

- The microalga during phycoremediation drastically reduced the sludge levels; the accumulation of sludge generated by conventional treatment methods has been the major problem for the industry

- Before commercialisation and industrial scaling-up, further studies are to be carried out for implementation at an industrial scale as well as for effective utilisation of biomass. Furthermore, India being a tropical country with plenty of sunshine is well suited for implementation of phycoremediation as a technology.

\section{Acknowledgements}

We thank the Secretary and Principal, R.K.M. Vivekananda College, Chennai 600 004, India, for providing us with the necessary infrastructure and facilities required for the study. Our thanks to the management and staff of the industry for the help rendered to us during the field studies. We are grateful to Mr. Sundaram Ramachandran, Scientific Publishing Services Pvt. 
Ltd., Chennai, for his help in language editing of the manuscript. We also thank the anonymous reviewer and the editor for their comments and suggestions, which helped greatly in improving the manuscript. Hanumantha Rao P, received financial assistance from the Department of Collegiate Education, Chennai 600 006, Tamil Nadu, India.

\section{References}

APHA (AMERICAN PUBLIC HEALTH ASSOCIATION) (2000) Standard Methods for Examination of Water and Wastewater $\left(21^{\text {st }}\right.$ edn.), American Public Health Association, Washington DC.

ARVIN E (1983) Observations supporting phosphate removal by biologically mediated chemical precipitation - a review. Water $S c i$. Technol. 15 43-63.

AZIZ MA and NG WG (1993) Industrial wastewater treatment using an activated algae-reactor. Water Sci. Technol. 28 71-76.

BECKER EW (1994) Microalgae - Biotechnology and Microbiology. Cambridge University Press, Cambridge.

BENEMAN JR, FOOPMAN BL, WEISSMAN JC, EISENHER DM and OSWALD WJ (1980) Cultivation on sewage of microalgae harvestable by microstrainer. Progress Report. Sanitary Engineering Research Laboratory, University of California, Berkeley, California.

BITTON G (1990) Wastewater Microbiology. Wiley-Liss, New York.

BOLAN NS, WONG L and ADRIANO DC (2004) Nutrient removal from farm effluents. Bioresour. Technol. 94 251-260.

BOROWITZKA MA (1998) Limits to growth. In: Wong Y-S and Tam NFY (eds.) Wastewater Treatment with Algae. Springer-Verlag, New York. 203-226.

COLAK O and KAYA Z (1988) A study on the possibilities of biological wastewater treatment using algae. Doga Biyoloji Serisi 12 18-29.

DE-BASHAN LE, MORENO M, HERNANDEZ J and BASHAN Y (2002) Removal of ammonium and phosphorus ions from synthetic wastewater by the microalgae Chlorella vulgaris coimmobilized in alginate beads with the microalgae growth-promoting bacterium Azospirillum brasilense. Water Res. 36 2941-2948.

DE LA NOÜE J, LALIBERTE G and PROULX D (1992) Algae and wastewater. J. Appl. Phycol. 4 247-254.

DRESBACK K, GHOSHAL D and GOYAL A (2001) Phycoremediation of trichloroethylene (TCE). Physiol. Mol. Biol. Plants 7 117-123.

DUNN K (1998) The Biotechnology of High Rate Algal Ponding Systems in the Treatment of Saline Tannery Wastewaters. PhD thesis. Rhodes University, Grahamstown, South Africa.

GANTAR M, OBREHT Z and DALMACIJA B (1991) Nutrient removal and algae succession during the growth of Spirulina platensis and Scenedesmus quadricauda on swine wastewater. Bioresour. Technol. 36 167-171.

HALLING-SØRENSEN B and JØRGENSEN SG (1993) The Removal of Nitrogen Compounds from Wastewater. Elsevier, Amsterdam, The Netherlands.

HAMMOUDA O, GABER A and ABDEL-RAOUF N (1994) Microalgae and wastewater treatment. Ecotoxicol. Environ. Saf. 31 205-210.

LALIBERTE G, PROULX, G, PAUW N and DE LA NOÜE J (1994) Algal technology in wastewater treatment. Ergebnisse der Limnologie 42 283-302.

LARSDOTTER K (2006) Microalgae for Phosphorus Removal from Wastewater in a Nordic Climate. PhD thesis. Royal Institute of Technology, Stockholm, Sweden.
MARA DD and PEARSON H (1986) Artificial freshwater environment: waste stabilization ponds. In: Rehm HJ and Reed G (eds.) Biotechnology. VCH Velagsgesellschaft, Weinheim. 177-206.

MUÑOZ R and GUIEYSSEA B (2006) Algal-bacterial processes for the treatment of hazardous contaminants: a review. Water Res. 40 2799-2815.

NAGASE H, YOSHIHARA K, EGUCHI K, OKAMOTO Y, MURASAKI S, YAMASHITA R, HIRATA K and MIYAMOTO K (2001) Uptake pathway and continuous removal of nitric oxide from flue gas using microalgae. Biochem. Eng. J. 7 241-246.

NICHOLS HW and BOLD HC (1965) Growth media - Fresh water. In: Stein JR (ed.) Hand Book of Physiological Methods. Cambridge University Press, Cambridge. 7-24.

NUNEZ VJ, VOLTOLINA D, NIEVES M, PINA P, MEDINA A and GUERRERO M (2001) Nitrogen budget in Scenedesmus obliquus cultures with artificial wastewater. Bioresour. Technol. 78 161-164.

NURDOGAN Y and OSWALD WJ (1995) Enhanced nutrient removal in high rate ponds. Water Sci. Technol. 31 33-43.

OLIVER RL and GANF GG (2000) Freshwater blooms. In: Whitton BA and Potts M (eds.) The Ecology of Cyanobacteria: Their Diversity in Time and Space. Kluwer, Dordrecht. 149-194.

OLGUÍN EJ (2003) Phycoremediation: key issues for cost-effective nutrient removal processes. Biotechnol. Adv. 22 81-91.

OSWALD WJ and GOTAAS HB (1957) Photosynthesis in sewage treatment. Trans. Am. Soc. Civ. Eng. 122 73-105.

OSWALD WJ, GOTAAS HB, GOLUEKE CG and KELLEN WR (1957) Algae in waste treatment. Sewage Ind. Wastes 29 437-457.

OSWALD WJ and GOLUEKE CG (1960) Biological transformation of solar energy. Adv. Appl. Microbiol. 2 223-262.

OSWALD WJ (1988) Micro-algae and waste-water treatment. In: Borowitzka MA and Borowitzka LJ (eds.) Micro-Algal Biotechnology. Cambridge University Press, Cambridge. 305-328.

OSWALD WJ (1995) Ponds in the twenty-first century. Water Sci. Technol. 31 1-8.

OSWALD WJ (2003) My sixty years in applied algology. J. Appl. Phycol. 15 99-106.

PHILIPOSE MT (1967) Chlorococcales. Kurup R (ed.) ICAR, New Delhi, India.

QUEIROZ MI, LOPES EJ, ZEPKA LQ, BASTOS RG and GOLDBECK R (2007) The kinetics of the removal of nitrogen and organic matter from parboiled rice effluent by cyanobacteria in a stirred batch reactor. Bioresour. Technol. 98 2163-2169.

ROSE PD, MAART BA, DUNN KM, ROWSWELL RA and BRITZ P (1996) High Rate algal oxidation ponding for the treatment of tannery effluents. Water Sci. Technol. 33 219-227.

ROSE PD (2002) Salinity, sanitation and sustainability; a study in environmental biotechnology and integrated wastewater beneficiation in South Africa. Vol. 1: Overview. WRC Report No: TT 187/02. Water Research Commission, Pretoria, South Africa.

SEDLAK R (1991) Phosphorus and Nitrogen Removal from Municipal Wastewater: Principles and Practice ( $2^{\text {nd }}$ edn.). Lewis Publisher, Ann Arbor, Michigan.

VENKATARAMAN LV and BECKER EW (1985) Biotechnology and Utilization of Algae - The Indian Experience. Department of Science and Technology, New Delhi, India.

ZHANG E, WANG B, WANG Q, ZHANG S and ZHAO B (2008) Ammonia-nitrogen and orthophosphate removal by immobilized Scenedesmus sp. isolated from municipal wastewater for potential use in tertiary treatment. Bioresour. Technol. 99 3787-3793. 